\title{
Autonomia versus controle dos trabalhadores: a gestão do poder no hospital
}

\author{
Autonomy versus worker's control: \\ power management in the hospital
}

Luiz Carlos de Oliveira Cecílio 1

\footnotetext{
1 Departamento de Medicina Preventiva e Social, Faculdade de Ciências Médicas, Unicamp, Rua da Tijuca 1302, Souza, Campinas, 13130-590, São Paulo, SP, Brasil lcecílio@correionet.com.br
}

\begin{abstract}
The article focuses on the theme of power within health organizations, particularly in hospitals, emphasizing the ever present tension between control versus autonomy in its management process. Carefully examined is the hypothesis that democratic and participative management models, with a strong publicization of the institutional life, have been seen as controllists by the workers - which could be an apparent paradox through its autonomy creation discourse. The creation of multiple devices or negotiation contexts, in which multiple organizational rationalities meet and are confronted, is said to be an alternative for a radically democratic management, supported by the idea which says that no macroactor (the direction or the government) has got the power of imprinting the rationality of the organization without facing a complex, permanent and dialogical negotiation process which would involve all the organizational actors.
\end{abstract}

Key words Power; Control; Autonomy; Management; Organization
Resumo O artigo enfoca a temática do poder nas organizações de saúde, em particular no hospital, dando ênfase à sempre presente tensão entre controle versus autonomia no seu processo de gestão. Examina-se, em particular, a hipótese de modelos de gestão democráticos e participativos, com forte publicização da vida institucional, estarem sendo vistos como controlistas pelos trabalhadores, o que seria um aparente paradoxo com seu discurso de criação de autonomia. A criação de múltiplos dispositivos ou contextos de negociação, nos quais se encontram e se confrontam as múltiplas racionalidades organizacionais, é apontada como alternativa para uma gestão radicalmente democrática, apoiada na idéia de que nenhum macroator (a direção ou o governo) tem o poder de imprimir a racionalidade da organização, sem enfrentar um complexo, permanente e dialógico processo de negociação que envolveria todos os atores organizacionais.

Palavras-chave Poder; Controle; Autonomia; Gestão; Organização 


\section{Apresentando o problema}

As questões ligadas ao poder e ao controle estão inevitavelmente presentes na vida das organizações. Para Amitai Etzioni o êxito de uma organização depende, em grande parte, de sua capacidade para manter o controle dos participantes (1989: 77). Ainda para o mesmo autor, a característica de artificialidade das organizações (...) torna inadequado o controle informal e impede que se confie na identificação com a tarefa. Quase nunca as organizações podem confiar que a maioria dos participantes interiorize suas obrigações e, sem outros incentivos, cumpra voluntariamente seus compromissos (idem: 78). Para Hall, o poder e o conflito estão no cerne da compreensão das organizações (1984: 93). Campos está dizendo coisa semelhante sobre as organizações de saúde ao afirmar que (...) não é possível operar sistemas de saúde sem certo grau de controle institucional (grifo atual). E daí o paradoxo. Como combinar liberdade com controle? (Campos, 1997: 230). Todos estes autores estão tomando, explicita ou implicitamente, a temática do poder no interior das organizações ao falarem de controle. Quem controla tem poder.

A hipótese trabalhada, neste artigo, é a de que determinado modo de se pensar a gestão dos serviços de saúde, em particular do hospital, de recorte democrático, descentralizado, com ênfase na autonomia, direção colegiada em todos os níveis da organização (Campos, 1992; Cecilio, 1994) é, paradoxalmente, visto como controlista por esses mesmos trabalhadores, para quem se supunha estar garantindo uma maior participação da gestão. As características gerais deste modelo, aplicado com variações em distintas experiências, podem ser apresentadas assim:

- explicitação da missão da organização no sentido dos compromissos e direcionalidade que assume perante o sistema de saúde e os usuários, inclusive na perspectiva da adoção de esquemas contratualistas com um agente externo, na linha dos contratos de gestão;

- adoção de organogramas horizontalizados ou "achatados" que resultam na diminuição dos níveis hierárquicos dentro da organização; - ênfase no trabalho em equipes que, de forma isolada ou agrupada, vai se constituir nas unidades básicas do sistema de direção;

- profissionalização da gerência destas unidades. O foco da gestão está na equipe e não nas corporações;
- constituição de grupos de apoio à gestão (GAG), ao nível das unidades, com formação multiprofissional, para apoio ao gerente no processo gerencial;

- ênfase na comunicação lateral entre as unidades ou equipes para a agilização do enfrentamento dos problemas do cotidiano;

- gestão colegiada em todos os níveis, que na verdade se resumem a dois: os colegiados nas unidades, constituídos pelo conjunto de seus trabalhadores e uma direção superior representada por um colegiado de gerentes formado pelos gerentes das unidades e com poder para definir a política da organização e avaliar o seu desempenho;

- profissionalização de uma área de desenvolvimento institucional ou de planejamento estratégico para apoio ao processo de implantação e consolidação do novo modelo;

- ênfase na utilização intensiva da informação, organizada em indicadores para o monitoramento contínuo do desempenho da organização;

- criação de políticas próprias de avaliação e gratificação de desempenho, de acordo com instrumentos previamente acordados com os trabalhadores;

- adoção de uma "caixa de ferramentas" (Merhy, 1997) que, em grande medida, é originária das propostas de gestão da qualidade para apoiar o processo gerencial;

- adoção de tecnologias leves de planejamento estratégico (Cecilio, 1997) para a elaboração de planos regulares da direção;

- criação de mecanismos formais e regulares tanto de avaliação da satisfação dos usuários como de intervenção direta dos mesmos no processo de gestão.

Os dados empíricos e de observação que dão suporte à hipótese trabalhada neste artigo já foram sistematizados em três trabalhos anteriores do autor. O primeiro deles, publicado na Revista da Administração Pública (Cecilio, 1997), analisa a forte resistência das corporações médicas e de enfermagem à implantação de um modelo de gestão mais descentralizado e com ênfase nas equipes, com evidente quebra - ou tentativa de - do forte "espírito de corpo" em um hospital de Porto Alegre (RS). Fica muito claro que a resistência a modelos mais democratizantes da gestão hospitalar encontra fortes resistências também por parte do corpo de enfermeiras e não só dos médicos, como aparentava ser. O segundo é um texto inédito que analisa quatro anos 
de trabalho com este tipo de modelo de gestão em um ambulatório de especialidades da Fundação Hospitalar de Minas Gerais (FHEMIG), situado em Belo Horizonte. Chamam atenção, neste trabalho, dois aspectos muito interessantes: a existência de conflitos entre o projeto da equipe e o projeto da instituição e uma evidente tensão entre a concepção de autonomia dos profissionais especialistas e das equipes e os mecanismos de avaliação criados pela direção, vistos como controlistas, apesar desta se orgulhar de estar trabalhando com um modelo de gestão democrático e com ênfase na autonomia. O terceiro trabalho é um relatório de avaliação de quatro anos de implantação do modelo de gestão descentralizado e participativo no Hospital São João Batista de Volta Redonda (RJ), elaborado como parte de uma pesquisa financiada pelo $\mathrm{CNPq}$, em andamento no DMPS/FCM/Unicamp. O relatório, se por um lado confirma as já conhecidas estratégias de não-adesão dos médicos a qualquer modelo que tenha alguma veleidade controlista, por outro aponta como as enfermeiras desenvolvem estratégias competentes de ocupar e hegemonizar novos dispositivos institucionais pensados para democratizar a vida da organização, inclusive como forma de se fortalecerem perante os médicos e vários movimentos internos de deslocamento e reconcentração de poder em instâncias pensadas como dispositivos para democratização da vida institucional.

A forma como esses processos de inovação gerencial são significados e/ou vividos por atores institucionais estratégicos poderia estar explicando, pelo menos parcialmente - mas com muita força - a baixa adesão às vezes observada nesses modelos de recorte participativo. Mesmo que outras explicações para essa baixa adesão - como as características do setor público, a dificuldade de se encontrar gerentes para esta nova função gerencial, entre outras - possam ser buscadas, tenta-se, aqui, mostrar que estes modelos, se implementados de fato, resultam em acentuado processo de distribuição de poder no interior da organização com todas as suas conseqüências. Trata-se, pois, neste artigo, das questões do poder no interior das organizações.

Vale dizer que esta não-adesão quase nunca assume a forma de confronto, mas de um silencioso boicote, uma espécie de resistência pacífica que resulta em eficaz arma contra as mudanças pretendidas pelos dirigentes. Fenô- meno semelhante foi observado quando da tentativa de implantar um projeto de democratização dos presídios no estado de São Paulo na década de 70 , conseqüência da resistência das coalizações internas que se sentiam ameaçadas pelo processo de abertura e maior controle dos presídios pela sociedade. Uma restruturação que "não pegou", no dizer de Fischer (1996: 79-82).

O que se pretende, então, é tentar iluminar o problema do aparente desinteresse ou baixa participação dos trabalhadores, nesses modelos participativos, a partir de outro ângulo, tomando como eixo analítico o colocarse no lugar do outro, tentando captar os possíveis sentidos de sua ação. Não vai nesta idéia, é bom que se esclareça, nenhuma adesão incondicional, a priori, à sociologia compreensiva, como ademais a qualquer outra corrente sociológica. Pelo contrário, assume-se, aqui, uma postura eclética, de diálogo com várias possíveis contribuições teóricas para a discussão do tema.

O problema é que não parecem restar muitas alternativas a esses modelos mais participativos e democráticos que não seja a adoção dos clássicos modelos de administração vertical, com linhas hierárquicas de mando muito bem definidas, no velho esquema fayolista ou, na melhor das hipóteses, na burocracia como tipo ideal weberiano. E não há controle, exercício explícito e implícito de poder, conflitos, nessa forma de se fazer gestão? Há, mas em configurações, desenhos, esquemas há muito sedimentados, acordados, impostos por uns sobre os outros, de forma que qualquer mudança é vista como ameaçadora e introduz um alto nível de instabilidade na organização. Mexer em modelo de gestão é mexer em esquemas de poder. Sempre se soube disto, é claro, mas talvez se tenha subestimado este fato na formulação e implementação de modelos alternativos de gestão. É bom que se esclareça, também, que esses vetores de poder ou esses campos organizacionais de exercício do poder ou essas relações de poder são múltiplos, não obedecem a um único padrão e envolvem, de forma muito variada, os diferentes trabalhadores. Por exemplo, no tradicional modo de se fazer a gestão em hospitais, os médicos gozam de alto grau de autonomia, não estando submetidos a praticamente nenhum mecanismo de controle. Os médicos têm muito poder nas organizações. No corpo de enfermagem, essas linhas de poder são mais marcadas quando se 
olha a linha vertical de comando que vai da enfermeira à auxiliar de enfermagem, mas são menos nítidas quando se olha a relação entre as enfermeiras e destas com os médicos e com a direção do hospital. Os mecanismos de controle e os graus de autonomia com que o pessoal administrativo exerce seu trabalho também obedecem a outros padrões e a outros esquemas relacionais, tanto internamente à administração, como na relação com os demais agrupamentos profissionais.

Pois bem, se é verdade que o corpo de enfermagem estaria submetido a uma relação assimétrica perante o poder médico, não seria de se esperar a incondicional adesão desses profissionais à implantação de um modelo de gestão mais democrático e participativo e que, por princípio, horizontalizaria mais as relações dentro da equipe, ou seja, distribuiria poder? Em termos. É fato que, na maioria das vezes, é possível observar uma maior adesão das enfermeiras a essas formas mais colegiadas de direção, chegando mesmo a hegemonizar certas instâncias por sua forte presença e participação, constituindo novos espaços de exercício de poder nesses novos arranjos institucionais Cecilio (1998a). Por outro lado, há também fortes resistências do corpo de enfermagem a essas formas mais transparentes de gestão, nas quais há uma forte publicização dos espaços de gestão e dos processos de trabalho, quase sempre muito privatizados, no sentido de atravessados por interesses particulares, por acordos intracorporação, que acabam sendo revelados Cecilio (1997).

Então, não é demais afirmar que qualquer mudança na atual forma de gestão deverá tomar como tema a questão do poder na vida organizacional, na perspectiva de compreender, da melhor forma possível, a configuração que assumem as relações de poder em cada situação particular. Vale destacar que o reconhecimento da singularidade de cada situação não invalida que se reconheçam certas regularidades presentes em quase todas as organizações: o forte poder médico traduzido em sua autonomia e na sua acentuada capacidade de impor disciplinas no hospital Carapinheiro (1993); a linha de mando fortemente hierarquizada da enfermagem; mas também estratégias de resistência dos subalternos, verdadeiras "linhas de fuga" ao poder instituído Lima (1998).

Trabalha-se, também, com a hipótese de que os conceitos de autonomia e controle, in- dissociavelmente ligados à categoria poder, tal como vêm sendo utilizados nas formulações de modelos de gestão que enfatizam a democratização, a descentralização, a participação e a autonomia, não estejam livres de ambigüidades e imprecisões que dificultam sua operacionalização.

\section{Algumas formas possíveis de se pensar o poder e a sua tradução em estratégias de controle nas organizações}

Não faz parte dos objetivos dispostos para este artigo uma revisão que conseguisse esgotar a temática do poder, mas apenas delimitar um certo campo problemático.

Uma primeira aproximação com o tema poderia ser a constatação de que o poder é, sempre, relacional, no sentido de que diz respeito às relações entre dois ou mais atores sociais, nas quais o comportamento de um é afetado pelo do outro. As partes numa relação de poder estão ligadas entre si pela dependência mútua. Em virtude da dependência mútua, é mais ou menos imperativo para cada uma das partes que ela seja capaz de controlar ou influenciar a conduta da outra (Hall, 1984: 93-94). A definição mais comumente aceita de poder é aquela dada por Weber (1991: 33) de que poder significa toda probabilidade de impor a própria vontade numa relação social contra resistências, seja qual for o fundamento desta probabilidade. Quase a mesma coisa está dizendo Dahl (1957), quando define: A tem poder sobre $B$, ̀̀ medida que pode levar $B$ a fazer algo que $B$ de outra maneira não faria. Para Foucault (1995) o exercício do poder consiste em conduzir condutas e em ordenar probabilidades. Governar entendido como estruturar o eventual campo de ação dos outros. O poder é um ato; é algo usado ou exercido. O poder só existe em ato, é um modo de ação de alguns sobre os outros.

Assume-se, então, que essas possibilidades concretas de uma parte controlar ou influenciar a conduta da outra, a ação de alguns sobre os outros ou alguém fazer algo que não faria, por imposição do outro, são manifestações visíveis ou a apresentação fenomênica do poder. São os rastros que o poder deixa no tecido imaterial das organizações, permitindo o seu estudo e localização. Mecanismos de controle são o poder manifesto nas organizações. Pode-se assumir, assim, que uma boa possibi- 
lidade de estudar a temática do poder nas organizações é desvelar como se estabelecem tais mecanismos de controle, que circuitos assumem, em que arranjos e formas de relação concretas eles se revelam nas vidas das organizações. Também é possível afirmar que, mesmo que por negação, a temática da autonomia está tratando da temática do poder. Falar em autonomia é também falar do exercício do poder, mas em outros circuitos, outros arranjos: distribuição, desconcentração, capilarização do poder.

Max Weber é um autor que tem centralidade na presente discussão em função da sua compreensão da mútua influência entre o poder de controle e a capacidade de justificar (legitimar) seu exercício. O poder exercido de forma legítima tem o sentido de autoridade. Conforme ensina a experiência, nenhuma dominação contenta-se voluntariamente com motivos materiais ou afetivos ou racionais referentes a valores, como possibilidades de sua persistência. Todas procuram despertar e cultivar a crença em sua legitimidade Weber (1991). Para este autor, há três tipos puros de dominação legítima: a de caráter racional, a de caráter tradicional e a de caráter carismático. Neste estudo, interessa, em particular, a dominação legítima de caráter racional, ou seja, aquela baseada na crença da legitimidade das ordens estatuídas e do direito de mando daqueles que, em virtude dessas ordens, estão nomeados para exercer a dominação (dominação legal) (p. 141). É o exercício do poder, ou da dominação, conforme prefere Weber, no interior das organizações formais. O tipo mais puro de dominação legal é aquele que se exerce por meio de um quadro administrativo burocrático (grifo original) (p. 144).

A temática do poder, quando trabalhada a partir da matriz teórica weberiana, traz sempre a idéia de consentimento e de obediência. Certo minimo de vontade de obedecer, isto é, de interesse (externo ou interno), faz parte de toda relação autêntica de dominação (p. 139). É Richard Hall que faz a provocante afirmação de que o resultado da maior parte dos atos de poder é a obediência, sendo o conflito mais exceção do que regra (Hall, 1984: 92). Etzioni considera que o grau de obediência ou o envolvimento dos membros de uma organização depende do tipo ou forma de poder empregados. Quanto maior a utilização de recursos simbólicos, como nas organizações normativas, maior o envolvimento dos trabalhadores. Quanto mais coercitiva, mais alienatória é a adesão. Quando são utilizados meios materiais para o controle, haveria uma adesão utilitária dos trabalhadores. $\mathrm{O}$ autor reconhece que não há formas puras de controle, à medida que nas organizações haveria uma combinação de sanções (pelo menos possibilidade de), de estímulos materiais (salários, gratificações, benefícios) e da utilização de símbolos (premiações, estímulos, o valor do cargo, etc.). Basta pensar em um hospital para se reconhecer o quanto estas formas de uso do poder se completam e são específicas para cada contexto.

As contribuições de Michel Foucault para a discussão sobre o poder representam um deslocamento importante em relação à concepção weberiana predominante no interior da TGA à medida que ele recusa a teoria da soma zero desta última. Entenda-se como soma zero a idéia de que, para alguém ter poder, alguém tem que perder poder. $\mathrm{O}$ poder seria uma soma fixa, tal que o poder de A implica no não-poder de B. Esse deslocamento de Foucault está caracterizado por três gupos de idéias principais. Primeiro, a idéia de que a dominação não se reduz à proibição, à repressão escancarada, não é apenas dotada do poder do não, não é só limitadora. O poder é produtor e organizador de forças, mais que controlador. O poder constitui sujeitos ao dobrá-los às suas pedagogias disciplinadoras. Segundo, o poder não é apenas representação jurídica. O poder é mais instaurador de normas que de leis. E, terceiro, não existe uma oposição binária entre dominadores e dominados, não há uma oposição de poder ao indivíduo. O poder é um conjunto de relações que formigam por toda a parte da espessura do corpo social Lebrun (1984). Interessa, em Foucault, a idéia de poder/saber, particularmente o que ele designou como o regime do saber, ou seja, a maneira como o saber circula, funciona e suas relações com o poder. Não há, nesse autor, uma teoria da hierarquia das formas de poder e ele faz uma distinção absoluta entre o poder jurídico (que o paradigma weberiano permite trabalhar) e o poder disciplinar. A abordagem do poder em Foucault, mais do que a idéia de acatamento, prevê a necessidade de contemplar a resistência aos efeitos do poder e prevê mesmo que, para compreender as relações de poder, seja necessário analisar as formas de resistência que lhe são oferecidas e os esforços para decompor estas relações Carapinheiro (1993). 
Para Foucault, é legítimo analisar as relações de poder em instituições bem determinadas, estas últimas constituindo um observatório privilegiado para as atingir (as relações de poder) - diversificadas, concentradas, ordenadas e levadas, parece, ao seu mais alto grau de eficácia; numa primeira abordagem é aí que podemos pretender ver aparecer a forma e a lógica de seus mecanismos elementares Foucault (1995). O autor nos adverte, no entanto, para o risco de se cair numa circularidade do tipo explicar o poder pelo poder ao se analisar as relações de poder a partir das instituições, quando é o inverso que deve ser feito: analisar as instituições a partir das relações de poder. Aqui, Foucault inverte, de fato, a lógica adotada pelos estruturalistas, que vêm as relações de poder muito marcadas (embora não só) pelos lugares ocupados pelos vários atores na estrutura formal. O próprio conceito de autoridade legal, em Weber, está muito assentado nos espaços institucionais ocupados pelos atores como uma das bases para a legitimação do exercício do poder.

Foucault, de qualquer forma, nos dá algumas pistas da possibilidade de nos apropriarmos da categoria poder para a análise das organizações. Uma delas é quando afirma que $o$ poder só existe em ato e se inscreve num campo de possibilidades esparso que se apóia sobre estruturas permanentes (grifo atual) Foucault (1995). A outra é quando estabelece alguns pontos para uma análise das relações de poder, dos quais destacam-se aqueles que possam ajudar a pensar as organizações enquanto estruturas permanentes. 1) Um sistema de diferenciações que permitem agir sobre a ação dos outros. Aqui o autor dá exemplos que podem ser remetidos à "estrutura” organizacional, quais sejam, diferenças de lugar nos processos de produção e diferenças jurídicas de estatuto. Para ele, toda relação de poder opera diferenciações que são, para ela, ao mesmo tempo, condições e efeitos (p. 246). 2) O tipo de objetivos perseguidos por aqueles que agem sobre a ação dos outros, que pode ser do acúmulo de lucros a operacionalidade de uma autoridade estatutária, passando pelo exercício de uma profissão, que são objetivos que se realizam em estruturas permanentes. 3) As modalidades instrumentais, que podem ir da ameaça das armas aos mecanismos de controle através de regras, explícitas ou não, como nas instituições. 4) As formas de institucionalização que remetem às estruturas jurídicas ou hierárquicas, podendo tomar forma de sistemas complexos dotados de aparelhos múltiplos, como no caso do Estado que se torna a instância de controle global e o princípio de regulação e, até certo ponto, de distribuição de todas as relações de poder num conjunto social dado. Apesar de reconhecer que as relações de poder estão cada vez mais governamentalizadas, ou seja, elaboradas, racionalizadas e centralizadas na forma ou sob a caução das instituições do Estado, Foucault enfatiza muito mais o fato de as relações de poder estarem enraizadas no conjunto da rede social, bem como a idéia de que as formas e lugares de governo dos homens uns pelos outros serem múltiplos numa sociedade, não privilegiando as organizações formais para o seu estudo.

Por que, então, nesta primeira aproximação com o tema do poder, se justificaria a citação de dois autores que constroem analíticas tão diferentes? Weber é referência obrigatória porque é dele a teorização sobre a burocracia na sua racionalidade legal-instrumental, baseada no princípio da autoridade, que é um paradigma ainda não superado, ou que, pelo menos, tem que se considerar, mesmo que seja para apontar inconsistências, na análise das organizações formais, inclusive dos hospitais. Foucault constrói outro paradigma que pode ajudar a iluminar, entre outras coisas, a singular inserção do médico no hospital, a partir da categoria saber-poder. Estas duas possibilidades de caminhos analíticos, utilizadas no hospital, serão retomadas no próximo item, em uma aproximação mais cuidadosa à problemática específica do hospital.

\section{A singularidade das relações de poder no hospital}

Vários autores reconhecem que o hospital moderno está longe de corresponder ao tipo ideal de burocracia de Weber. Pelo contrário, apesar da existência de uma estrutura administrativa burocrática nos hospitais, haveria neles um sistema dual de autoridade. Smith considera que a hierarquia de autoridade no hospital inclui uma linha de autoridade que desce da administração ao pessoal hospitalar colocado na base da pirâmide hierárquica, fixando-se de uma forma mais ou menos explícita a autoridade e responsabilidade atribuídas a cada nível da hierarquia e aos respectivos sistemas de comunicação. No entanto, de uma análise 
mais atenta e minuciosa da organização cotidiana do hospital, emerge uma linha de autoridade, com origem no poder carismático que os médicos detêm pelo fato de possuírem o saber capaz de curar doenças e de salvar vidas e na competência técnica que lhes permite opor e sobrepor às exigências da administração, as exigências decorrentes do trabalho clínico e a defesa dos privilégios profissionais no interior do hospital Carapinheiro (1993). Convivem, então, na organização, dois princípios de autoridade que são a base para a permanente disputa de poder e ocorrência de conflitos. De um lado, a necessidade de controle ou de governar que a administração superior tem, a fim de imprimir racionalidade ao funcionamento do hospital, a partir de objetivos gerais de eficiência e eficácia; de outro, os médicos que são ciosos da auto-regulação profissional e da autonomia individual de cada um deles. Trata-se, então, da disputa entre a adoção de regras de natureza burocrática ou de natureza mais profissional.

Goss construiu o conceito de advisory bureaucracy para os hospitais universitários. $O$ traço principal que caracteriza a advisory bureaucracy não são as regras, mas os conhecimento técnicos específicos e os princípios orientadores para a aplicação destes conhecimentos. A conseqüência principal disto é que os mecanismos de controle baseados em ordens ou regras fixas são substituídos pela supervisão baseada no conhecimento (Goss apud Carapinheiro, 1993: 49).

Stelling e Bucher sugerem os conceitos de autonomia elástica, responsabilidade (accountability e monitoring) em substituição aos conceitos de autoridade e hierarquia tão caros aos teóricos da burocracia. O conceito de autonomia elástica parte da definição de autonomia como a aptidão que os indivíduos dispõem numa situação de trabalho para determinar a natureza dos problemas com que se defrontam e para saberem resolvê-los. É elástica no sentido de que não existe um domínio fixo de autonomia nem se liga de forma inerente a nenhuma posição hierárquica (p. 50). Uma pessoa só tem autonomia quando possui o poder de controlar seu próprio trabalho e, decorrente deste controle, é que pode ser responsável pelas ações que desencadeia. Muitos dos conflitos no hospital decorrem dessa disputa entre os profissionais ou equipes querendo o maior controle possível dos recursos para seu trabalho (lógica da autonomia/lógica da eficácia) e a direção (lógica do controle/lógica da eficiência).

Friedson alerta para a simplificação que seria adotar a dicotomia que considera a autoridade administrativa como arbitrária e a autoridade com origem na especialização técnica e no poder profissional como funcionalmente neutra e naturalmente produtora de adesão e consentimentos. Para ele, a relação entre médicos e os não-médicos, quando regulada pela autoridade originada na competência profissional, tem conseqüências muito semelhantes àquelas resultantes da utilização da autoridade burocrática, visíveis na experiência dos outros trabalhadores e dos clientes. Assim se explica, por exemplo, que muitos dos atributos de rigidez, mecanicismo, autoritarismo e coordenação inadequada, com que se têm caracterizado os serviços de saúde, provêm mais da sua organização profissional do que das suas características burocráticas (...) A racionalidade que orienta a ação dos profissionais, muitas vezes aproxima-se ou tende a incorporar alguns aspectos da racionalidade burocrática que forneçam eficácia institucional aos projetos de autoridade. Basta pensar nas facetas burocráticas e nos efeitos compulsivos de negociação, submissão ou impotência que se reveste o exercício das diversas dimensões do poder dos profissionais face aos participantes nas organizações e face àqueles que beneficiam dos seus serviços (Friedson apud Carapinheiro 1993: 5153). Uma das conclusões que se pode tirar destas constatações é que qualquer modelo de gestão de pretensão democrática, assentado na idéia da criação de sujeitos coletivos, deva se ocupar do desmonte não apenas das linhas verticais de mando, mas dessa verdadeira trama de relações de poder que se tecem em todas as direções, sem correspondência necessária na hierarquia formal, por exemplo, ao nível da equipe. Os modelos de gestão que preconizam substituição da direção hierarquizada e verticalizada das corporações profissionais por formas mais colegiadas de gestão, ao nível das unidades de trabalho (Campos, 1992; Cecilio, 1994), podem estar subestimando os circuitos de poder e de controle que existem nesse nível local e que não seriam modificados apenas com a quebra das linhas verticais de comando.

Parece que, a partir deste ponto, alguns aspectos da analítica do poder de Foucault poderiam ser destacados nessa aproximação ao tema do poder no hospital: a) os médicos são 
os únicos profissionais realmente autônomos no hospital; b) a natureza do poder médico é um poder-saber. A indeterminação é uma característica do saber médico, que o protege da rotinização e desqualificação. A indeterminação surge como uma mística inerente à produção e reprodução do conhecimento, apenas adquirida por quem tem a posse deste conhecimento, insuscetivel de ser especificada e rotinizada $e$, objeto de um permanente processo de interpretação (Atkinson apud Carapinheiro, 1993: $74)$; c) é a indeterminação que separa o saber médico dos saberes periféricos e dos saberes profanos e é, simultaneamente, a cláusula que assegura a não ingerência de quaisquer formas de regulação externas à profissão (p. 74-75); d) o poder médico no hospital se localiza no serviço, e este se constitui no domínio específico do desenvolvimento das relações de poder no hospital, cujo instrumento é a disciplina médica, entendida como saber e como controle social (p. 79); e) são as formas de funcionamento e circulação do saber médico que constituem o saber dos profissionais de enfermagem como um saber periférico, e o saber do doente como um saber profano, restringindo e delimitando de forma precisa o poder dos enfermeiros como um sub-poder, ou seja, um poder cujo alcance, condições de exercício e estratégias são definidos pelo poder médico, e não concedendo ao doente qualquer forma de poder oficialmente reconhecida (p. 79); f) o pessoal de enfermagem pode ser considerado uma plataforma de mediação privilegiada entre os doentes e o poder médico.

Há, em Foucault, uma perspectiva de incompatibilidade entre poder médico e poder jurídico. Esta perspectiva poderia ser questionada por outra que defenderia a possibilidade de transferência de poderes entre esses dois tipos de poder, ou seja, a possibilidade de poder médico e administrativo colonizarem-se mutuamente. A experiência brasileira de gestão das santas casas parece autorizar esta última hipótese e, mais do que isso, são freqüentes os casos do poder administrativo se encontrar estruturalmente dominado pelo modelo de racionalidade médica. Basta lembrar o poder dos médicos funcionarem como gatekeepers dos hospitais e determinarem, a partir desse ponto, toda a lógica da administração do hospital. Até este ponto, falou-se do conceito de controle. Caberia, agora, tentar apreender, com mais cuidado, a temática da autonomia.

\section{A autonomia na gestão dos hospitais: problematizando um conceito}

A idéia de autonomia remete, numa primeira aproximação, a um plano mais macro, como visão de projeto de sociedade, autonomia da sociedade entendida como poder latente e possibilidade real que a sociedade possui de governar e organizar a si mesma (Motta 1981: 133). Esta idéia está, por exemplo, em Proudhon, considerado o inspirador das experiências históricas de criação de um regime autogestionário. O termo autogestão é recente e pode ser considerado como sinônimo de autonomia. Para Proudhon, que não usava o termo autogestão, a autonomia não se restringiria à simples administração de uma empresa por seu pessoal. Ele deu, pela primeira vez, à sua concepção, o significado de um conjunto social de grupos autônomos, associados tanto nas suas funções econômicas, quanto nas funções políticas. A sociedade autogestionária, em Proudhon, é a sociedade organicamente autônoma, constituída de um feixe de autonomias de grupos se auto-administrando, cuja vida exige a coordenação, mas não a hierarquização (p. 133). A idéia de autonomia subordina-se e ao mesmo tempo embasa um projeto libertário de sociedade. A Comuna de Paris de 1871 é considerada como marco histórico da possibilidade de uma sociedade autogerida.

Para Motta, a autogestão caracteriza-se pela autonomia dos empregados nas decisões empresariais, desde o processo de formulação de diretrizes internas e divisão do trabalho à distribuição da renda (Motta, 1980: 7). A autogestão consiste no exercício coletivo do poder (Motta, 1981). Para esse mesmo autor, a autogerência ou autonomia constituiria uma forma de $a$ ) eliminar a alienação do trabalhador em relação à decisão sobre produção e distribuição dos recursos que trabalha; $b$ ) superar efeitos negativos da divisão do trabalho, diminuindo a rigidez das formas hierárquicas e criando condições para aumentar a cooperação e responsabilidade; (...) d) melhorar as condições humanas de trabalho; $e$ ) instituir como direito a democracia organizacional visando ao desenvolvimento (p. 21). A autogestão significaria, então, a forma mais radical e global de participação, significando a autonomia dos membros de uma organização para definir os destinos, os métodos e os resultados da ação da organização em que trabalham. A autogestão seria uma forma de eliminar a alienação do trabalhador em relação à 
decisão sobre produção e distribuição dos recursos com que trabalha (p. 28).

No institucionalismo, vamos encontrar a idéia de que autogestão é, ao mesmo tempo, o processo e o resultado da organização independente que os coletivos se dão para gerenciar sua vida. As comunidades instituem-se, organizamse e estabelecem-se de maneiras livres e originais, dando-se os dispositivos necessários para gerenciar suas condições e modos de existência Baremblitt (1992).

A autogestão (autonomia), no sentido restrito e claro do termo, é incompatível com os sistemas de propriedade privada ou estatal dos meios de produção, só podendo existir em condições de propriedade social. Se a autogestão é examinada no conceito mais restrito e ortodoxo do termo, isto é, liberdade de decisão por parte dos membros de uma organização para deliberar sobre os destinos de sua organização e os resultados de seu trabalho, ela é praticamente inexistente Motta (1981). O mesmo está dizendo Baremblitt quando reconhece que a autogestão não é tarefa fácil: a prova está em que as iniciativas auto-analíticas e augestivas não se caracterizam por seu sucesso. Elas têm aparecido muitas vezes na história e muitas vezes têm sido destruídas ou sufocadas. E as que hoje insistem em existir lutam duramente contra um conjunto imenso de forças sociais que tentam recuperá-las, incorporá-las (1992: 24).

Motta reconhece algumas dificuldades inerentes ao processo de gestão ao analisar, por exemplo, a experiência da ex-Iugoslávia: a) a alienação das decisões torna-se difícil de ser eliminada devido à falta de conhecimento dos trabalhadores. Apesar de sindicatos e órgãos políticos alimentarem ideologicamente os conselhos, a falta de conhecimento técnico-profissional por parte dos dirigentes prejudica o grau real de influência nas decisões de caráter mais complexo sobre os destinos da empresa; b) a atenuação da rigidez hierárquica encontra sérios obstáculos nos valores culturais da percepção da autoridade. Os vestígios das reminiscências tradicionais da hierarquia social não são facilmente destrutíveis e se projetam no meio organizacional. Após a decisão coletiva, a estrutura hierárquica organizacional é facilmente reconstituída e acentuadamente enfatizada; c) a motivação econômica é uma grande fonte de definição dos objetivos isolados de eficiência e produtividade, quase ao estilo do taylorismo, embora em decorrência da autogerência. Quanto maior a eficiência, maio- res os salários e a participação nos lucros. À medida que as decisões coletivas perturbam esses objetivos, tendem naturalmente a ser revistas, bem como a recompensa do trabalho coletivo tende a ser feita de acordo com avaliações no nível individual Motta (1980).

É possível expor pelo menos dois pontos que tornam problemática a utilização do conceito de autonomia nas organizações de saúde, em geral, e nos hospitais em particular, pelo menos na forma como tem sido aplicada: a) a autogestão nasceu como uma concepção de gestão social ou da visão da sociedade autogestionária - inicialmente nas teorias anarquistas e depois em várias teorias socialistas. A sua utilização na teoria gerencial é um necessário deslocamento do macro para o micro, que pode resultar no comprometimento da radicalidade das formulações originais à medida que, desde Proudhon, reconhece-se que não há autonomia isolada em uma empresa se não for articulada com feixes de autonomias, que atravessam toda a sociedade. Basta pensar na atual tendência de heteronomia na nossa sociedade para pensar o quanto fica contra-hegemônica a idéia de se trabalhar a autonomia no espaço mais micro. O quanto ela pode ser de difícil compreensão, mesmo enquanto proposta, para os trabalhadores; b) a autonomia, na sua significação precisa, não poderia ser praticada tanto nas empresas privadas como nas organizações governamentais, apenas nas organizações sociais exatamente pela presença do governo, com tudo o que isso significa na tradição pública no Brasil: ingerência política, clientelismo, interesses político-partidários externos à vida organizacional, etc. É inevitável, por definição, a heteronomia nas organizações governamentais.

De que autonomia trata-se, então, quando esse termo é utilizado na construção de modelos de gestão participativa com forte ênfase na autonomia? Pode-se dizer que a ênfase na autonomia na gestão dos serviços de saúde pode ser entendida a partir de duas vertentes: 1) a forte influência do pensamento de esquerda no pensamento sanitário brasileiro poderia justificar a construção de modelos de gestão comprometidos com ideais de uma sociedade autogestionária. Experiências desenvolvidas na gestão de rede de serviços de saúde, desde 1980, na região de Campinas, parecem trazer esta marca, mesmo que partindo de uma avaliação de conjuntura muito otimista e irreal (Cecilio, 1994: Cap. 2). Nesta medi- 
da, pensar que a autonomia em saúde tem a ver com a idéia, adotada pelo autor, de que a autonomia é tanto meio como fim em si mesma! A conquista de graus crescentes de autonomia pelos trabalhadores, através da ampliação de sua capacidade de autoanálise e autogestão, para além de razões ligadas à eficácia dos serviços de saúde, faz parte de um projeto de sociedade; 2) reconhecimento de que o trabalho em saúde tem, por sua natureza, um forte componente de autonomia. A configuração dessa autonomia é dada, fundamentalmente, pela presença do médico na equipe de saúde. As considerações sobre a autonomia do trabalho médico, nas atuais condições brasileiras, já foram desenvolvidas em pelo menos dois trabalhos referenciais de Campos $(1997,1992)$ e em excelente revisão recente de Capozzolo (1997). Do ponto de vista gerencial, no hospital, essa autonomia é basicamente do médico, na medida em que o pessoal de enfermagem tem sua prática cotidiana engessada na forma fayolista da hierarquia rígida de poder e em alguns fundamentos tayloristas de separação entre pensar e fazer, de fragmentação do trabalho e ênfase nas tarefas. Merhy (1987)faz um deslocamento de sua atenção e de suas investigações para a autonomia que existe no micro do micro, ali onde ocorre o trabalho vivo em saúde, no encontro de subjetividades entre o trabalhador e o usuário, valorizando essa autonomia do trabalho em ato. São poucas suas referências e preocupações com os constrangimentos estruturais. De qualquer forma, nos dois autores, os sistemas de gestão teriam de dar conta da problemática da autonomia, uma vez que os trabalhadores de saúde operam com relativo grau de autonomia, apesar dos constrangimentos a que estão submetidos Campos (1997).

Para concluir este tópico, é possível, então, dizer que tem-se utilizado o conceito de autonomia com certa imprecisão, quando se trata da gestão hospitalar. Em primeiro lugar, é forçoso reconhecer o quanto tem-se estado afastado de certo ideal autogestionário implícita ou explicitamente presente nas formulações iniciais de modelos de gestão democráticos, participativos, horizontalizados, com forte ênfase na autonomia. Esse afastamento do ideal autogestionário se dá seja porque se tem trabalhado nos burocráticos espaços governamentais com suas rígidas características de heteronomia e heterocefalia, seja porque se tem subestimado, de alguma forma, o peso do con- texto, da moldura ou do macro que destrói incessantemente, no nascedouro, qualquer experiência contra-hegemônica, portadora de qualquer idéia de autogestão. Em segundo lugar, tem-se que reconhecer o quanto o paradigma de autonomia trabalhado na saúde ainda é a autonomia do médico, a despeito dos esforços para pensar a autonomia da equipe de uma forma mais ampliada. Afinal, seria possível apontar pelo menos uma experiência real, que demonstrasse a superação efetiva dos modos fayolista e taylorista de se organizar o cuidado de enfermagem nos hospitais? Seria possível apontar uma única experiência em que os médicos, enquanto estamento profissional (não enquanto um ou outro caso isolado...) houvessem aberto mão de um mínimo que fosse de sua autonomia real em nome da construção de novas relações no interior da equipe e no trato com os clientes, no sentido da construção da autonomia ampliada da equipe? O quanto os modelos de gestão que trabalham a autonomia conseguem penetrar nesse campo de relações de poder? De que autonomia, afinal, está-se tratando nesses modelos?

\section{Ainda a antinomia autonomia versus controle}

Retoma-se, aqui, a hipótese levantada no início do texto, de que os modelos de gestão participativa e democrática e construtores de autonomia, paradoxalmente, são vistos como controlistas pelos trabalhadores; poderia estar aí uma das explicações para as dificuldades para a sua implementação. De fato, outro conceito a ser problematizado é o de equipe ou de trabalhadores de saúde. Na verdade, estes conceitos ocultam múltiplos estamentos profissionais, portadores de poderes/saberes muito assimétricos e que configuram arranjos institucionais muito complexos, instituídos nos seus interesses, arranjos, ocultamentos e esquemas de todos os tipos. Estes instituídos são o que se poderia chamar de tensamente estáveis. A mudança seria vista, sempre, como ameaça. Assim, modelos de gestão com forte ênfase na publicização de espaços, na transparência da gestão do cotidiano, na contratualização, na avaliação pública dos resultados dos trabalhos e, inclusive, numa verdadeira análise de processos de trabalho (os "fluxogramas analisadores" são um bom exemplo) são vistos como ameaçadores por esses trabalhadores. 
Portanto, quando se trata da implantação de novos modelos de gestão, trata-se de responder algumas questões cruciais: Que mudança se deseja? Quem deseja a mudança? Quem está propondo a mudança? A quem interessa a mudança? Quem banca a mudança? Como a mudança do modelo de gestão contribui para mudança? Trata-se, pois, de se reconhecer que há atores muito distintos, com múltiplos interesses, com inserções diferenciadas, com controle de recursos de poder diferenciados e que trabalhar uma equipe ou uma unidade de trabalho, ou mesmo um colegiado de unidade pode ser, no limite, uma idealização. Idealização, por exemplo, supor que a gestão colegiada, no sentido de garantir que todos os trabalhadores tenham direito a voz e voto, nas unidades de trabalho, seja garantia do surgimento automático de um sujeito coletivo capaz de conduzir a unidade de forma autônoma, se determinada. Já se tem indicações de pelo menos duas coisas bem marcadas que acontecem nesses colegiados de unidade organizados nas unidades de produção dos hospitais: a primeira é que os médicos, sistematicamente, não participam desse espaço, não os legitimando, portanto, como espaço de controle, como de fato poderiam ser; a segunda é que as enfermeiras (não o corpo de enfermagem) hegemonizam esse espaço como um novo espaço de poder, conservando rigorosamente a linha de mando em relação ao corpo de enfermagem, à medida que se mantém a rígida divisão de tarefas. $\mathrm{O}$ grupo de apoio à gestão, pensado como grupo de apoio multidisciplinar ao gerente da unidade, torna-se uma trincheira de poder da enfermagem, inclusive para algum enfrentamento com os médicos Cecilio (1998 a,b). Nessa medida, podemos considerar quatro blocos distintos de atores no interior da equipe de saúde e seus distintos projetos ou formas de significar um modelo de gestão participativa: a) os médicos que vêem a idéia de colegiado da unidade, planilhas, comissão de revisão de óbitos, discussão de caso clínico, comissão de prontuários, etc. como algo que atenta claramente contra sua prática autônoma. Têm tudo a perder com o novo modelo de gestão. Fazem oposição clara ou velada. Tentam vencer pela deslegitimação, pela ausência; b) as enfermeiras, por formação profissional e pelos modelos fayolista e taylorista com que gerenciam se reconhecem mais nesses instrumentos de controle. Para elas, tais instrumentos poderiam significar (pe- la primeira vez!) uma possibilidade de alguma forma de controle institucional sobre os médicos. Razão para estratégias de adesão ao modelo. Por outro lado, o colegiado de unidade, a horizontalização das relações com o restante da equipe de enfermagem (os subalternos) podem abrir muito o jogo, explicitar esquemas e acertos entre enfermeiros, inclusive questionamentos da autoridade por parte dos subalternos. Por estas razões, pode gerar estratégias de oposição, como a experiência também demonstra (Cecilio, 1997); c) o pessoal de enfermagem (todos, menos as enfermeiras), em princípio, seriam os que mais ganhariam com a democratização da vida organizacional por serem os mais submetidos; portanto seria de se esperar estratégias de adesão por parte deles. Não é bem assim, à medida que, como bem revela Foucault, as relações de poder comportam contra-reações, estratégias dos dominados, que no espaço singular do hospital são muito criativas: do absenteísmo à recusa de substituição da colega faltosa no outro setor. A publicização da gestão revela também os esquemas dos de baixo; d) os demais profissionais (os psicólogos, assistentes sociais, fisioterapeutas, etc.) são numericamente inexpressivos na equipe e não chegam a pesar como estamento. Em geral, aderem às estratégias hegemônicas, hora aliando-se a um, hora a outro grupo, ou coalizão com o mais poderoso.

Para Campos, a democratização de serviços de saúde pressupõe uma certa concentração de poder politico suficiente para abrir canais de participação ou, pelo menos, para garantir espaços abertos, de baixo para cima, pelas bases. (...) Nos últimos anos, algumas organizações conseguiram democratizar-se. Em todas elas constatou-se uma combinação de concentração de poder e, portanto, um certo grau exacerbado de controle sobre o sentido do trabalho em saúde, com reformas de organogramas e das relações de poder Campos (1997). Aqui poderia ser apontada uma aparente contradição: se a democratização implica em concentração de poder e um certo grau exacerbado de controle, esta democratização é para quem? Pode ser uma democratização da instituição do ponto de vista da cidadania, do seu usuário, o que não é pouco, mas nunca do ponto de vista do trabalhador de saúde, que vê tal modelo de gestão como controlista, que sente na pele um certo grau exarcebado de controle sobre o sentido do trabalho! Então, como foi dito um pouco acima, se a construção da autonomia é um fim 
em si, permaneceria o desafio de se (re)definir que autonomia é esta que está se querendo construir, na medida em que é necessário que as autonomias hoje existentes (não só do médico que é a mais evidente, mas de todos os trabalhadores de saúde em algum grau) sejam recolocadas em outras bases, com outro sentido e que este sentido seja compartilhado pelos trabalhadores.

Não se trataria, também, de trabalhar com a idéia de criar canais de participação para as bases, quando se viu que não há, no hospital, nada que se pareça com bases, mas um jogo muito mais elaborado de relações de poder que comportam tudo, menos vetores de cima para baixo e vice-versa.

Merhy (1998), em trabalho recente, reconhece que: a) o modelo assistencial que opera nossos serviços é organizado dentro da ótica hegemônica do modelo médico neoliberal; b) são forças sociais que têm interesses e os disputam com as outras forças que estão definindo as conformações tecnológicas (p. 12); c) a missão dos serviços e de desenhos tecnológicos é dada pelos interesses sociais que no momento são mais poderosos e considerados legítimos (p. 15). Por tudo isto, fica claro que promover mudanças na atual forma de gestão e funcionamento do hospital implica entrar firme na problemática da distribuição de poder. Segundo Merhy, para superar a atual conformação dos serviços de saúde, que operam sob as lógicas dos núcleos de tecnologias duras e leve-duras, seria necessário "operar com alguns dipositivos que possibilitam redefinir os espaços de relações entre os vários atores envolvidos nestes processos, alterando as missões do estabelecimento, ampliando os modos de produzir saúde (...) Entretanto, diante de uma missão já a priori distinta, este processo se impõe como que mais naturalmente (...) Neste caso, vemos que o núcleo cuidador é o que deverá se impor, o que favorecerá, inclusive, $a$ diminuição das relações de dominação (grifo atual) que se estabelecem entre os vários profissionais (...) (p. 16). Estas afirmações do autor implicam em entrar firme no campo das relações de poder por, pelo menos, duas razões: 1) operar alguns dispositivos implica em alguém ou algum ator com controle de recurso de poder ou revestido de autoridade suficiente para bancar, seja pela negociação, seja pela imposição mesmo, o novo modelo de se fazer a gestão do cotidiano e dos processos de trabalho; 2) também adotar uma missão $a$ priori distinta implica em mobilizar poder, mesmo que essa adoção seja resultado de um amplo processo de negociação e formação de consenso, como aliás deve necessariamente ser para ter algum sentido.

O que há de mais provocador nas formulações do autor é a ênfase nas estratégias de mudança organizacional no espaço da micropolítica dos processos de trabalho, ali onde se dá a interseção de subjetividades e se realiza o trabalho vivo em saúde, apoiadas na idéia de que trabalho vivo é potência e de que seria possível desdobrar esta potência em novas linhas de poder e novos instituintes Merhy (1997). Tais possibilidades de abordagem da gestão, amparadas em boa medida na esquizoanálise de Guatarri e Deleuze, poderiam ser vistas como sinérgicas ou, necessariamente, tendo que ser acompanhadas de estratégias intermediárias, do tipo criação de contextos de negociação (como se verá mais à frente), que façam a mediação entre as negociações e complexas relações que se estabelecem ao nível da micro-política do processo de trabalho e a estrutura. Quem sabe uma frutífera aproximação de temas e saberes da teoria das organizações - ainda hegemonizada pelo paradigma estrutural-funcionalista mas com importantes correntes internas que buscam novos referenciais centrados nos sujeitos - com o institucionalismo.

Vale também uma reflexão sobre a idéia de que diante de uma missão a priori distinta, esse processo (a adoção de novo modo de se fazer a assistência, mais cuidador) se impõe como que mais naturalmente. Na verdade, nada nesse espaço micro se impõe naturalmente, tudo é objeto de permanente disputa e construção. A idéia, em si, da construção de um projeto coletivo, que possa se traduzir na definição da missão ou de metas organizacionais é, em si, problemático, como já discutido por Cecilio (1998a). Haveria uma permanente disputa entre metas formais e metas operacionais de pessoas ou coalizões, de maneira que, no limite, a missão seria uma reificação, uma pretensão de racionalidade que não encontraria sustentação na realidade.

É bom que se deixe claro que o reconhecimento destas dificuldades, longe de significar justificativa para o abandono destes esforços de abertura e arejamento da gestão dos hospitais, traduz-se, apenas, na necessidade de que novos dispositivos de participação, de negociação, de abertura sejam pensados e prati- 
cados, a partir de um olhar mais cuidadoso e apurado para este complexo universo das relações dentro do hospital.

\section{Como forma de conclusão: a necessidade da negociação}

Por tudo o que foi dito sobre a singularidade do hospital - espaço habitado por múltiplos atores, atravessado por múltiplas racionalidades, interesses, coalizões, disputas, controles de poderes/saberes - um projeto democrático para a saúde deverá considerar, necessariamente, o tema da negociação, com tudo de radical que esse termo possa comportar. Para encerrar este artigo, apresenta-se o conceito de negociação tal qual desenvolvido em dois campos teóricos que, afinal de contas, se alimentam ou pelo menos dialogam com uma fonte comum: a sociologia compreensiva de Max Weber. De um lado, a teoria da ação comunicativa desenvolvida por Habermas e utilizada por Rivera para uma análise da Teoria das Organizações; do outro, a idéia de ordem negociada trabalhada por Strauss, tomando como paradigma o interacionismo simbólico.

Para Rivera, a teoria da ação comunicativa permitiria analisar uma organização como o locus do conjunto de significados que os atores organizacionais atribuem à sua práxis, ou seja, como a sede de conexões de sentido que os atores fazem e procuram negociar em um contexto dialógico caracterizado pela multiplicidade de pontos de vista e por uma atitude orientada pelo entendimento. Nesta perspectiva, o contexto valorativo, normativo e subjetivo que envolve os atores e que se define externa e internamente às organizações desempenha um papel relevante na ação Rivera (1995). O que há de mais central nesta afirmação é o abandono de qualquer postura logocêntrica, ou seja, a pretensão de ser possível imprimir à organização uma espécie de totalização da racionalidade instrumental dada por um macroator, que pode ser a organização, ou a direção, totalização que escaparia às referências de sentido de atores específicos (p.91). Este tipo de reflexão poderia ser aplicado ao comentário feito anteriormente de que, muitas vezes, a implantação de um modelo de gestão democrático e participativo, por mais que pareça justo e correto - a partir de uma perspectiva logocêntrica! - é, de fato, imposto e vivido como instrumental pelos demais atores que não participam da sua formulação e da decisão da sua implementação. O contexto dialógico destacado por Rivera assenta-se na negociação e é orientado para entendimento.

O modelo da ordem negociada desenvolvido por Strauss é muito adequado para análise de hospitais por considerar: a) a vida das organizações como o resultado de uma vasta e variada gama de negociações; b) a existência, ao nível de um mesmo escalão do hospital, de diferenças internas relativamente ao estatuto e ao poder, assim como à sabedoria de "como obter as coisas"; c) as regras que orientam as ações dos vários profissionais estão longe de estarem clara e inequivocamente estabelecidas e de abarcarem todas as áreas de atividades do hospital; d) criam-se constantemente regras informais para regular ações e situações no preenchimento dos hiatos deixados na regulamentação formal, cruzando-se constantemente, no cotidiano do hospital, as regras formais e informais; e) no hospital, além do fato de ser um lugar altamente profissionalizado, reunindo profissionais das mais distintas formações, há uma grande diversidade de ideologias relativas a questões tão importantes como a etiologia e o tratamento das doenças, constituindo-se, desde logo, esses elementos como condição de base para o desencadeamento de múltiplos processos de negociação. (Strauss apud Carapinheiro, 1993: 63).

A partir destas constatações, o autor acha que só haveria um único acordo ou missão comum para o hospital: recuperar o doente para o mundo exterior em condições de saúde física e mental. Este seria o cimento simbólico da organização. O resto seria uma construção social precária, permanentemente negociada e renegociada entre os vários atores. Construída no campo do interacionismo simbólico, esta seria uma alternativa às teorias tradicionais da determinação estrutural das condutas organizacionais. Tal paradigma forja-se em três conceitos básicos: negociação, para referir-se às interações e às estratégias levadas a cabo pelos participantes; contextos de negociações, que seriam os traços relevantes dos lugares onde ocorrem as negociações, condicionando-as; contexto estrutural, como as circunstâncias mais amplas que transcendem os contextos de negociação. Na verdade, os contextos de negociação poderiam ser vistos como os dispositivos de negociação e suas formas de funcionamento: são o número de 
negociadores, a sua experiência de negociação e quem estão representando; o tipo de negociação: única, repetida, seqüencial, em série ou múltipla; o relativo equilíbrio de forças exibido pelas partes envolvidas na negociação; a sua visibilidade, em termos das suas características serem manifestas ou latentes; o número e a complexidade dos problemas em negociação; a clareza da legitimidade dos limites dos problemas negociados; as opções tomadas para evitar ou interromper a negociação (Carapinheiro, 1993: 64). O que há de instigante e, pode-se considerar, operacionalizável, nessas formulações, é a idéia de que os contextos de negociação fariam a mediação (seriam mediadores) entre os contextos estruturais (estruturas) e os processos negociativos. Poderiam ser vistos como dispositivos com historicidade, construídos e abandonados pelos atores sociais, em um permanente processo de negociação e renegociação.

Parece que as questões apontadas antes (Que mudança se deseja? Quem está propondo a mudança? A quem interessa a mudança? Como conduzir a mudança?) poderiam ser trabalhadas no interior desses dispositivos. São questões, em primeiro lugar, que não podem ser respondidas por um só ator ou força social, por mais até que nos pareça existir uma que é a melhor ou que está do lado bom. São questões que remetem ao campo da ética, das finalidades, da missão, dos compromissos, de tudo, enfim, que dá a singularidade de uma organização. Não há solução para a antinomia controle versus autonomia fora do debate que se trava nesse campo substantivo: o campo da relação entre os homens, no nosso caso, das relações dos trabalhadores entre si, dos trabalhadores e da gerência e dos trabalhadores com os usuários. Resta, talvez, uma só opção diante da constatação do campo minado de poder que são os hospitais: o uso que se quer fazer do poder. Uns poderão pensar em usar os vetores ou linhas de força do poder para reforçar as estrututuras, para reproduzir, para conservar, velhos e novos privilégios. Outros poderão estar atentos a linhas de fugas, a possibilidades de novos arranjos e novos vetores que tornem a organização um lugar mais leve e iluminado para quem nela trabalha e dela necessita, mesmo que temporariamente, para recuperar seu modo de andar a vida. 


\section{Referências}

Baremblitt G 1992. Compêndio de Análise Institucional e Outras Correntes: Teoria e Prática. Rosa dos Ventos, Rio de Janeiro.

Campos gws 1992. A Reforma da Reforma. Hucitec, São Paulo.

Campos GWS 1997. Subjetividade e administração de pessoal: considerações sobre modos de gerenciar trabalhos em equipes de saúde. In EE Merhy \& RT Onocko, Agir em Saúde um Desafio para o Público. Hucitec, São Paulo.

Carapinheiro G 1993. Saberes e Poderes no Hospital: uma Sociologia dos Serviços Hospitalares. Afrontamento, Porto.

Cecilio LCO 1994. Inventando a Mudança na Saúde. Hucitec, São Paulo.

Cecilio LCO 1997. A modernização gerencial dos hospitais públicos: o difícil exercício da mudança. $R A P$ 31(3): 36-47.

Cecilio LCO 1998a. Relatório de avaliação do funcionamento do modelo de gestão do Hospital São João Batista de Volta Redonda (RJ). Pesquisa CNPq. Campinas, mimeo.

Cecilio LCO 1998b. A importância da definição do projeto como balizador da mudança organizacional. Campinas, mimeo.

Etzioni A 1974. Análise Comparativa das Organizações Complexas: sobre o Poder, o Engajamento e seus Correlatos. Zahar, Rio de Janeiro.

Etzioni A 1989. Organizações Modernas. Pioneira, São Paulo.

Fischer RM 1996. O círculo do poder: as práticas invisíveis de sujeição nas organizações complexas. In
MTL Fleury \& RM Ficher, Cultura e Poder nas Organizações. Atlas, São Paulo.

Foucault M 1995. O sujeito e o poder. In P Rabinow \& H Dreyfus, Foucault uma Trajetória Filosófica: para Além do Estruturalismo e da Hermenêutica. Forense, Rio de Janeiro

Hall RH 1984. Organizações: Estrutura e Processos. Prentice Hall do Brasil, Rio de Janeiro.

Lebrun G 1984. O que é o Poder. Abril Cultural/Brasiliense, São Paulo.

Lima RCD 1998. A Enfermeira: uma Protagonista que Produz o Cuidado Cotidiano do Trabalho em Saúde. Tese de doutorado, Unicamp, Campinas, mimeo.

Merhy EE 1987. Em busca do tempo perdido: a micropolítica do trabalho vivo em saúde. In EE Merhy \& RT Onocko, Agir em Saúde um Desafio para o Público. Hucitec, São Paulo.

Merhy E 1998. O desafio da tutela e da autonomia: uma tensão permanente do ato cuidador. Campinas, mimeo.

Motta FP 1981. Burocracia e Autogestão. Brasiliense, São Paulo.

Motta PR 1980. Autogestão: a experiência empresarial iugoslava. RAP 14(1): 7-24

Motta PR 1981. Participação na gerência: uma perspectiva comparada. RAP 15(4): 4-33.

Rivera FJU 1995. Agir Comunicativo e Planejamento Social (Uma Crítica ao Enfoque Estratégico). Fiocruz, Rio de Janeiro.

Weber M 1991. Economia e Sociedade: Fundamentos da Sociologia Compreensiva. Universidade de Brasília, Brasília. 